www.nature.com/bcj

HOW TO MANAGE...

\title{
How I treat splenomegaly in myelofibrosis
}

\author{
F Cervantes \\ Hematology Department, Hospital Clínic, IDIBAPS, University of Barcelona, Barcelona, Spain
}

Symptomatic splenomegaly, a frequent manifestation of myelofibrosis (MF), represents a therapeutic challenge. It is frequently accompanied by constitutional symptoms and by anemia or other cytopenias, which make treatment difficult, as the latter are often worsened by most current therapies. Cytoreductive treatment, usually hydroxyurea, is the first-line therapy, being effective in around $40 \%$ of the patients, although the effect is often short lived. The immunomodulatory drugs, such as thalidomide or lenalidomide, rarely show a substantial activity in reducing the splenomegaly. Splenectomy can be considered in patients refractory to drug treatment, but the procedure involves substantial morbidity as well as a certain mortality risk and, therefore, patient selection is important. For patients not eligible for splenectomy, transient relief of the symptoms can be obtained with local radiotherapy that, in turn, can induce severe and long-lasting cytopenias. Allogeneic hemopoietic stem cell transplantation is the only treatment with the potential for curing MF but, due to its associated morbidity and mortality, is usually restricted to a minority of patients with poor risk features. A new class of drugs, the JAK2 inhibitors, although also palliative, are promising in the splenomegaly of MF and will probably change the therapeutic algorithm of this disease.

Blood Cancer Journal (2011) 1, e37; doi:10.1038/bcj.2011.36; published online 7 October 2011

Keywords: myelofibrosis; therapy; splenomegaly; splenectomy; JAK2 inhibitors

\section{Introduction}

Myelofibrosis (MF) is a chronic myeloproliferative neoplasm (MPN) characterized by bone marrow fibrosis, extramedullary hemopoiesis with splenomegaly and leukoerythroblastosis in blood. ${ }^{1}$ The disease can appear de novo (primary MF or PMF) or as evolution of a previously known MPN, either polycythemia vera (PV) (post-PV MF) or essential thrombocythemia (ET) (postET MF). ${ }^{2}$ Irrespective of MF being primary or to follow a previous MPN, once it is diagnosed, its clinical and histological characteristics and prognosis are essentially the same. MF is a clonal proliferation of a pluripotent hemopoietic stem cell, ${ }^{3,4}$ in which the resulting abnormal cell population releases several cytokines and growth factors in the bone marrow that lead to the appearance of marrow fibrosis and stroma changes, and colonizes extramedullary organs such as the spleen and the liver. ${ }^{2}$ The mutation V617F in the JAK2 gene is present in more than a half of patients with PMF or post-ET MF, and in $95 \%$ of those with post-PV MF. ${ }^{5-8}$ Mutations in the MPL gene the gene

Correspondence: Dr F Cervantes, Hematology Department, Hospital Clínic, IDIBAPS, University of Barcelona, Villarroel 170, Barcelona 08036, Spain.

E-mail: fcervan@clinic.ub.es

Received 20 May 2011; revised 13 July 2011; accepted 10 August 2011 of the thrombopoietin receptor) are observed in $4-8 \%$ of patients with PMF and post-ET MF but not in post-PV MF. 9,10 These molecular findings have contributed to a better understanding of the pathogenesis of MF, but the diagnosis of the disease remains mainly of exclusion.

MF is an infrequent disease that usually affects elderly people. ${ }^{11}$ Currently, median survival approaches 6 years, but there is a wide variability, ranging from less than 1 year to more than 2 decades. ${ }^{11} \mathrm{~A}$ number of prognostic factors have been identified and, recently, important progress has been made in the prognostic stratification of MF patients, both at diagnosis ${ }^{11}$ and during the disease evolution, ${ }^{12,13}$ with four prognostic groups with markedly different survival having been recognized (Table 1).

MF is a heterogeneous disease, not only with regard to its prognosis but also to its clinical and hematologic manifestations. Around $30 \%$ of patients are asymptomatic at diagnosis and can remain in this fashion for variable periods of time. ${ }^{11}$ However, most patients have symptoms already at presentation, most frequently derived from anemia and splenomegaly, and constitutional symptoms. To date, allogeneic hemopoietic stem cell transplantation (allo-HSCT) is the only therapy with the potential for curing $\mathrm{MF}^{14-16}$ but, in practice, owing to the advanced age of most patients, the lack of donor and, especially, the substantial morbidity and mortality associated with the procedure, allo-HSCT is restricted to a few patients, usually included within the intermediate- 2 and high-risk prognostic categories. Therefore, for the majority of patients with MF, the disease remains incurable, with its therapy being merely palliative. Because of this, and given the heterogeneity of the clinical manifestations of the MF, it is important to adjust the treatment to the characteristics of the disease in each individual patient.

\section{The splenomegaly of MF}

Splenomegaly, one of the most characteristic features of MF, is due to extramedullary hemopoiesis (also called myeloid metaplasia), ${ }^{17}$ which affects not only the spleen but also the liver (and, for this reason, hepatomegaly and alterations of the liver function often coexist) and, more unfrequently, other sites such as the lung, the kidney, the central nervous system, the lymph nodes or the skin. The spleen is palpable in up to $90 \%$ of MF patients at presentation. ${ }^{11}$ In this sense, it must be noted that if the spleen is not palpable at diagnosis and does not become palpable after 1 or 2 years, the possibility of other conditions such as myelodysplasia, which can also cause cytopenias and marrow fibrosis, should be excluded by careful examination of the bone marrow histopathologic features. ${ }^{18}$ Symptoms from splenomegaly usually correlate with spleen size. Thus, some patients with moderate splenomegaly may not have local symptoms initially. However, as the spleen 
Table 1 Current prognostic stratification of patients with primary myelofibrosis

\begin{tabular}{lccc} 
Variable $^{\mathrm{a}}$ & IPSS & DIPSS & DIPSS-plus \\
\hline Age $>65$ years & + & + & + \\
Constitutional symptoms & + & + & + \\
$\mathrm{Hb}<10 \mathrm{~g} / \mathrm{dl}$ & + & + & + \\
Leukocytes $>25 \times 10^{9} / \mathrm{l}$ & + & + & + \\
Circulating blasts $>1 \%$ & + & + & + \\
Transfusion need & & & + \\
Platelet count $<100 \times 10^{9} / \mathrm{l}$ & & & + \\
Unfavorable kayotype & & & + \\
(+8, $-7,-7 \mathrm{q},-5,-5 \mathrm{q}$, iso 17q, & & & \\
inv (3), 12p-, 11q23 rearrangement) & & &
\end{tabular}

Abbreviations: DIPSS, dynamic IPSS; IPSS, international prognostic scoring system.

${ }^{a}$ Each variable scores 1 point, except 2 points for $\mathrm{Hb}<10 \mathrm{~g} / \mathrm{dl}$ in the DIPSS.

progressively increases, it produces mechanical discomfort in the left part of the abdomen, occasionally episodes of severe pain in the left upper quadrant irradiating to the shoulder and due to splenic infarctions, early saciety and diarrhea. These symptoms are frequently associated with profound cachexia and fatigue, accentuation of pre-existing cytopenias and, sometimes, signs of portal hypertension. Of note, despite its clinical relevance in MF, splenomegaly is not per se a poor prognostic factor of the disease, as it is usually observed in patients displaying other well-recognized unfavorable prognostic factors, such as severe anemia, constitutional symptoms or marked leukocytosis. ${ }^{11}$

\section{Treatment of splenomegaly}

It is generally agreed that, if patients with MF have no symptoms, a wait-and-see approach is a reasonable option, with treatment being delayed until significant changes are observed. ${ }^{19}$ It is likely that such conservative approach will change as soon as more effective therapies for the disease will become available. The above wait-and-see policy also applies to asymptomatic splenomegaly, especially taking into account that MF patients have often concurrent cytopenias that may worsen following treatment institution.

\section{Myelosuppressive therapy}

For MF patients with marked and symptomatic splenomegaly, myelosuppressive drugs are considered as the first-line therapy, with hydroxyurea being the drug of choice. ${ }^{20-22}$ Although hydroxyurea has been (and still is) the drug most frequently used in this setting, information on its efficacy in MF has been based on a few reports that included a scarce number of patients. ${ }^{20,21}$ In this sense, in a recent publication from our group on the results of hydroxyurea therapy in $40 \mathrm{MF}$ patients with 'hyperproliferative' disease, ${ }^{22}$ symptomatic splenomegaly was the reason for treatment initiation in $45 \%$ of patients. The starting dose was $500 \mathrm{mg} /$ day and it was subsequently adjusted to the individual efficacy. In those patients who responded, the required dose to maintain the response was variable, ranging from $500 \mathrm{mg}$ to $2 \mathrm{~g}$ daily. According to the International Working Group for MF Research and Treatment (IWG-MRT) criteria, ${ }^{23}$ response in splenomegaly was $40 \%$, including disappearance of the palpable splenomegaly in 4 patients and a $>50 \%$ reduction in spleen size in 12 patients. Median duration of the response was 13.2 months, being long lasting in some patients (range: 3-126.2 months). Coincidently with hydroxyurea treatment, worsening of the anemia or appearance of pancytopenia was observed in almost a half of the patients, requiring administration of erythropoietin-stimulating agents, which were effective almost exclusively in patients with inadequate erythropoietin serum levels $(<125 \mathrm{U} / \mathrm{l})$ and nontransfusion-dependant anemia, or danazol. Therefore, to avoid the development or the accentuation of a pre-existing anemia, I usually start at a dose of $500 \mathrm{mg} /$ day, following the patient every 3-4 weeks during the initial phase of treatment to allow for dose titration. Once the appropriate dose is found, controls can be delayed to every $2-3$ months, unless the patient requires red blood cell transfusions. Oral or leg ulcers, the most characteristic extrahematologic toxicity of hydroxyurea, occasionally develop, usually in association with prolonged administration and high doses of the drug.

Busulfan, an alkylating drug, can also be used to treat symptomatic splenomegaly ${ }^{24}$ but, due to its prolonged effect and the risk of provoking long-lasting cytopenias, it requires a close control of the patients, making it inconvenient in clinical practice. Busulfan is contraindicated in the presence of leukocytes $<4 \times 10^{9} / \mathrm{l}$ or platelets $<100 \times 10^{9} / \mathrm{l}$, as the drug accumulates in the bone marrow, where it continues exerting its effect for several weeks. I have treated with busulfan a number of MF patients resistant or intolerant to hydroxyurea, who were not eligible for other therapies. In these cases, I usually give a low dose (2 mg/day) and follow the patients closely (every 3-4 weeks) to watch for possible development of leukopenia $\left(<4 \times 10^{9} / \mathrm{l}\right)$ or thrombocytopenia $\left(<100 \times 10^{9} / \mathrm{l}\right)$, which mandate immediate treatment stop. The drug was effective in some of the patients, with a progressive effect on spleen size being observed over the months. Once treatment was stopped because of decreasing hematologic values, some of the patients could remain untreated for several months, until spleen increase, accompanied by recovery of the hematologic values, led to treatment reinstitution.

Low-dose melphalan (2.5 mg for 3 days a week) yielded favorable responses in 66 of 99 patients with hyperproliferative MF. ${ }^{25}$ Splenic size, leukocytosis and thrombocytosis normalized in $23 \%, 86 \%$ and $93 \%$ of patients, respectively. Anemia improved in 12 of 20 patients not requiring transfusion and 6 of 16 became transfusion independent. However, the leukemogenic potential of melphalan probably explains its scarce use in clinical practice.

In patients with massive, refractory splenomegaly, intravenous courses of cladribrine (2-CdA), a purine nucleoside analog, given once-monthly for $4-6$ months, produced around $50 \%$ of responses that were mostly durable, with a median duration of 6 months after treatment discontinuation. ${ }^{26}$ Severe cytopenia was the main toxicity. It must be noted, however, that use of the above drug in MF is off-label.

\section{Interferon}

Despite in vitro data suggesting that interferon- $\alpha$ (IFN) could correct bone marrow fibrosis, in practice, the contribution of this drug to the treatment of MF has been minor, if any, owing to its limited efficacy and its frequent hematologic and extrahematologic toxicity, which leads to treatment discontinuation in the majority of patients. ${ }^{27-29}$ Recently, promising results have been reported with the use of the pegylated form of IFN. ${ }^{30}$ However, the mid-term toxicity of pegylated IFN in other diseases is not 
negligible and its effects in the long run not yet known, especially considering the advanced age of most MF patients. It is, therefore, quite unlikely that pegylated IFN could have a relevant role in the therapy of MF.

\section{Immunomodulatory drugs}

The immunomodulatory drugs, which include thalidomide, lenalidomide and pomalidomide, are a group of drugs that inhibit several cytokines and have antiangiogenic effects. They are used in patients with MF, alone or in combination with prednisone. ${ }^{31-35}$ Side effects are frequent, especially in the case of thalidomide (neurological toxicity) and lenalidomide (myelosuppression), and the responses are seen mostly in the anemia, whereas the drugs rarely have a substantial activity in the splenomegaly. Therefore, I would not recommend this type of therapy for MF patients with marked, symptomatic splenomegaly.

\section{Splenectomy}

Splenectomy involves a substantial risk in patients with MF. ${ }^{36-38}$ In a single-institution series, operative morbidity was $31 \%$ and mortality $9 \%$, usually during the 3-month post-splenectomy period. ${ }^{38}$ Main complications are bleeding (especially hemoperitoneum), infections and thrombosis. In addition, massive hepatomegaly due to compensatory myeloid metaplasia of the liver develops in 16-24\% of patients, some of which die from liver failure. ${ }^{39}$ Post-splenectomy thrombocytosis that increases the risk of thrombosis, especially in the splenoportal vein tract, ${ }^{40}$ is observed in $20 \%$ of patients. Following splenectomy, a higher rate of blast transformation has also been registered in one study, ${ }^{41}$ although this was not confirmed by others.

Splenectomy can be considered in MF patients with heavily symptomatic splenomegaly refractory to drug treatment, severe constitutional symptoms, transfusion-dependent anemia (including uncontrollable hemolysis) unresponsive to therapy and portal hypertension secondary to the increased portal flow. ${ }^{38}$ As no survival prolongation from splenectomy has been demonstrated, the risks of splenectomy should be carefully balanced against the possible benefits in every individual patient, in order to restrict the procedure to those patients most likely to benefit from it. Given the risks associated with the procedure, other factors such as the patient's comorbidities and life expectancy must also be taken into account.

In the series of the Mayo Clinic, durable responses in constitutional symptoms, transfusion-dependent anemia, portal hypertension and severe thrombocytopenia were obtained in $67 \%, 23 \%, 50 \%$ and $0 \%$ of cases, respectively. ${ }^{38}$ From the above results, it can be inferred that splenectomy has no role in the treatment of the thrombocytopenia of MF. Beside, thrombocytosis would be a relative contraindication to splenectomy, given the high probability of provoking uncontrollable thrombocytosis and thrombosis, especially in the splenoportal vein tract, because of the additional effect of the local injury during the surgical procedure. ${ }^{40}$. Therefore, if platelets are above the normal range and, despite this, splenectomy is decided, it is advisable to lower the platelets with hydroxyurea before surgery to around $200 \times 10^{9} / \mathrm{l}$ and to maintain them at this level in the post-operative period to reduce the risk of thrombosis. ${ }^{42}$ In addition, once it is made sure that peritoneal bleeding has not occurred within the first $24 \mathrm{~h}$ post surgery, prophylactic anticoagulation with low-weight molecular heparin should be instituted and maintained for at least 4-6 weeks. Peritoneal bleeding, the most life-threatening complication of splenectomy in these patients, usually occurs during the first $24 \mathrm{~h}$ following surgery. This complication can be related to the presence of thrombocytopenia but also to the existence of abnormalities of the platelet function in these patients. Because of this, I usually transfuse platelet concentrates immediately after spleen removal in all patients with platelet counts $<150 \times 10^{9} /$. I also do it in patients who actually develop peritoneal bleeding, in conjunction with the surgical measures aimed at stopping bleeding. By applying this measure, the incidence of this complication has dramatically dropped in my center and no mortality from this origin has been further observed. However, this personal approach is not supported by any randomized study.

With regard to the question of splenectomy or no before allo-HSCT, given the morbidity and mortality of splenectomy versus the faster hematologic recovery post transplant, ${ }^{14}$ splenectomy preceding transplantation is controversial. Although the current tendency is not to perform splenectomy routinely as preparation for transplantation, ${ }^{16}$ it seems reasonable to carry out the procedure in patients with massive splenomegaly, taking into account the higher risk of graft failure in such cases. However, this scenario will probably change with the availability of the JAK2 inhibitors, which are highly effective in reducing the splenomegaly in a high proportion of MF patients.

\section{Radiation therapy}

Splenic radiation can be used to reduce the spleen size and procure symptom relief. ${ }^{43-45}$ Total doses range from 0.15 to 65 Gy per course, administered in a fractioned form. It can be indicated in poor candidates to surgery and for palliation of severe pain from spleen infarct, but its effect is not durable, whereas the risk of severe and long-lasting cytopenias, with subsequent infection and bleeding, is high, probably due to an effect on the circulating progenitors. ${ }^{43,46}$ Therefore, routine use of splenic irradiation in patients with MF should not be recommended. In this sense, in an attempt to prolong the therapeutic effect of splenic irradiation while avoiding pancytopenia, an induction-maintenance strategy, consisting of administration of lower radiation doses during induction followed by maintenance with the same or lower doses, was recently reported to control not only the splenomegaly but also the signs of disease acceleration in two MF patients. ${ }^{47}$ On the other hand, splenic radiation to reduce the spleen size in preparation for splenectomy is not advised, given the higher rate of post-surgical bleeding observed in such cases, ${ }^{43}$ probably related to the development of splenic adhesions to the abdominal wall and the surrounding viscera.

\section{JAK2 inhibitors}

The discovery of the JAK2 mutation triggered the development of molecular-targeted therapies for the MPNs, with this especially applying to MF, given the lack of an appropriate therapy for many of these patients. However, for the time being, the expectations that the JAK2 inhibitors could reproduce the success of the tyrosine kinase inhibitors in chronic myeloid leukemia have not been substantiated. To date, information on the use of JAK2 inhibitors in MF is available for four drugs in clinical development: ruxolitinib (formerly known as INCB018424), TG101348, CEP-701 and CYT387, whereas 
Table 2 Summary of JAK2 inhibitors currently under clinical development in myelofibrosis

\begin{tabular}{lcc}
\hline Drug & Study phase & $\begin{array}{c}\text { Effect on } \\
\text { splenomegaly }\end{array}$ \\
\hline Ruxolitinib (INCB018424) & 3 & +++ \\
TG101348 & $1 / 2$ & +++ \\
CEP-701 & 2 & ++ \\
CYT387 & $1 / 2$ & +++ \\
SB1518 & $1 / 2$ & +++ \\
AZD1480 & $1 / 2$ & $\mathrm{NA}$ \\
\hline
\end{tabular}

Abbreviation: NA, not available.

other agents are also being tested (Table 2). These agents are usually administered to patients with intermediate-2 or high-risk MF, including PMF and post-PV/ET MF.

Ruxolitinib, an oral JAK1/JAK2 inhibitor, was given to $153 \mathrm{MF}$ patients in a phase $1 / 2$ trial. $^{48}$ Treatment was well tolerated, with thrombocytopenia as the dose-limiting toxicity. At the dose of $15 \mathrm{mg}$ twice daily, half of the patients had a clinical response, mainly in the splenomegaly and the constitutional symptoms. In responding patients, the response is usually dramatic but also drug- and dose-dependant, as treatment discontinuation or dose reductions because of side effects are rapidly followed by spleen increase and reappearance of constitutional symptoms. A small proportion of patients become transfusion independent and the same proportion have accentuation of pre-existing anemia. Of note, the response was independent of the patient's JAK2 mutational status, whereas no difference was noted between PMF and post-PV/ET MF. The effect on JAK2V617F allele burden was limited, and there was no significant reduction in the marrow fibrosis. Normalization of several pro-inflammatory cytokines was noted and this was correlated with symptomatic improvement, a fact that may be ascribed to the anti-JAK1 activity of the drug. Two different phase 3 multicenter studies (COMFORT-I and COMFORT-II) have been carried out and their results have recently been presented. ${ }^{49,50}$ The first one ${ }^{49}$ compared ruxolitinib versus placebo in 309 patients and the second one ${ }^{50}$ ruxolitinib with best-available therapy in 219 patients. Both trials have attained the primary endpoint of $>35 \%$ reduction in spleen size, as measured by imaging techniques, at 24 or 48 weeks of treatment start, respectively, and, based on these results, application for the drug approval is currently in progress. Ruxolitinib is a good palliative treatment for a half of MF patients with significant splenomegaly. Given its palliative nature, cost considerations will be important in deciding if it should be given to all MF patients with significant splenomegaly or if it could be used as a second-line therapy for patients not responding or losing the response to hydroxyurea.

TG101348 is an inhibitor with preferential activity in JAK2. In a phase $1 / 2$ study with 59 patients, ${ }^{51}$ dose-limiting toxicity was an increase in the serum amylases, without clinical signs of pancreatitis. Gastrointestinal adverse events were frequent but usually moderate and transient. Worsening of anemia, thrombocytopenia and neutropenia occurred in 35\%, 24\% and 10\% of the patients, respectively. At 6 months of treatment, almost $60 \%$ achieved a $>50 \%$ decrease in splenomegaly. The responses were independent of the JAK2V617F mutational status, but a $>50 \%$ decrease in the allele burden was reported in $40 \%$ of mutated patients. Symptomatic response was achieved in $50-75 \%$ and, as opposed to ruxolitinib, improvement in constitutional symptoms did not correlate with changes in pro-inflammatory plasma cytokine levels.
CEP-701 achieved clinical improvement in 6 of $22 \mathrm{MF}$ patients. ${ }^{52}$ However, gastrointestinal toxicity was remarkable, with diarrhea, nausea and vomiting in $72 \%, 50 \%$, and $27 \%$, respectively. No effect on JAK2V617F allele burden or proinflammatory cytokines was documented.

In a phase $1 / 2$ study with $108 \mathrm{MF}$ patients, ${ }^{53}$ CYT387 produced a response in palpable spleen according to the IWG-MRT criteria in $45 \%$ of cases, whereas resolution of constitutional symptoms was observed in the majority of patients. Of note, of the 42 patients evaluable for anemia response, $50 \%$ responded, including $58 \%$ of those who were transfusion dependent. Grade 3-4 thrombocytopenia was observed in $25 \%$ of patients, while hyperlipasemia and headache were the most characteristic non-hematologic side effects. The above observation of a substantial response rate of the anemia with CYT387A as compared with other JAK2 inhibitors can be of clinical interest and warrants confirmation in a larger number of patients.

Longer follow-up is required to define the role of the JAK2 inhibitors in the treatment of MF. The trade-offs between clinical activity and toxicity will be the determinant to choose the right drug. Beside, information on the possible extra-hematologic effects in the long term is needed. This having being said, it is quite likely that the JAK2 inhibitors will have a major role in the treatment of MF in the coming years, especially for splenomegaly and constitutional symptoms.

\section{Conflict of interest}

The author declares no conflict of interest

\section{Acknowledgements}

This work has been supported in part by the Grants RETICS RD06/ 0020/0004 and FIS PI10/00236 from the Instituto de Salud Carlos III, Spanish Ministry of Health.

\section{References}

1 Barosi G. Myelofibrosis with myeloid metaplasia: diagnostic definition and prognostic classification for clinical studies and treatment guidelines. J Clin Oncol 1999; 17: 2954-2970.

2 Mesa RA, Verstovsek S, Cervantes F, Barosi G, Reilly JT, Dupriez B et al. Primary myelofibrosis (PMF), post polycythemia vera myelofibrosis (post-PV MF), post essential thrombocythemia myelofibrosis (post-ET MF), blast phase PMF (PMF-BP): consensus on terminology by the International Working Group for Myelofibrosis Research and Treatment (IWG-MRT). Leuk Res 2007; 31: 737-740.

3 Jacobson RJ, Salo A, Fialkow PJ. Agnogenic myeloid metaplasia: a clonal proliferation of hematopoietic stem cells with secondary myelofibrosis. Blood 1978; 51: 189-194.

4 Buschle M, Janssen JW, Drexler H, Lyons J, Anger B, Bartram CR. Evidence of pluripotent stem cell origin of idiopathic myelofibrosis: clonal analysis of a case characterized by a N-ras gene mutation. Leukemia 1988; 2: 658-660.

5 Kralowics R, Passamonti F, Buser AS, Teo SS, Tiedt R, Passweig JR et al. A gain-of-function mutation of JAK2 in myeloproliferative disorders. N Engl J Med 2005; 352: 1779-1790.

6 Baxter EJ, Scott LM, Campbell PJ, East C, Fouroclas N, Swanton S et al. Acquired mutation of the tyrosine kinase JAK2 in human myeloproliferative disorders. Lancet 2005; 365: 1054-1061.

7 Levine RL, Wadleigh M, Cools J, Ebert BL, Wernig G, Huntly BJ et al. Activating mutation in the tyrosine kinase JAK2 in polycythemia vera, essential thrombocythemia and myeloid metaplasia with myelofibrosis. Cancer Cell 2005; 7: 387-397. 
8 James C, Ugo V, Le Couedic JP, Staerk J, Delhommeau F, Lacout $\mathrm{C}$ et al. A unique clonal JAK2 mutation leading to constitutive signaling causes polycythemia vera. Nature 2005; 434: 1144-1148.

9 Pikman Y, Lee BH, Mercher T, McDowell E, Ebert BL, Gozo M et al. MPLW515L is a novel somatic activating mutation in myelofibrosis with myeloid metaplasia. PloS Med 2006; 3: 1140-1151.

10 Pardanani AD, Levine RL, Lasho T, Pikman Y, Mesa RA, Wadleigh $M$ et al. MPL515 mutations in myeloproliferative and other myeloid disorders: a study of 1182 patients. Blood 2006; 108: 3472-3476.

11 Cervantes F, Dupriez B, Pereira A, Passamonti F, Reilly JT, Morra $\mathrm{E}$ et al. A new prognostic scoring system for primary myelofibrosis based on a study of the international working group for myelofibrosis research and treatment. Blood 2009; 113: 2895-2901.

12 Passamonti F, Cervantes F, Vannucchi A, Morra E, Rumi E, Pereira A et al. A dynamic prognostic model to predict survival in primary myelofibrosis: a study by the international working group for myeloproliferative neoplasms research and treatment. Blood 2010; 115: 1703-1708.

13 Gangat N, Pardanani A, Hanson CA, Van Dyke DL, Begna KH, Vaidya $\mathrm{R}$ et al. DIPSS-Plus: a refined dynamic international prognostic scoring system(DIPSS) for primary myelofibrosis that incorporates prognostic information from karyotype, platelet count and transfusion status. J Clin Oncol 2011; 29: 392-397.

14 Guardiola P, Anderson JE, Bandini G, Cervantes F, Runde V, Arcese $\mathrm{W}$ et al. Allogeneic stem cell transplantation for agnogenic myeloid metaplasia: a European Group for Blood and Marrow Transplantation, Societé Française de Greffe de Moelle, Gruppo Italiano per il Trapianto del Midollo Osseo, and Fred Hutchinson Cancer Research Center Collaborative Study. Blood 1999; 93: 2831-2838.

15 Ballen KK, Shrestha S, Sobocinski KA, Zhang MJ, Bashey A Bolwell BJ et al. Outcome of transplantation for myelofibrosis. Biol Bone Marrow Transplant 2010; 16: 358-367.

16 Kröger N, Holler E, Kobbe G, Bornhäuser M, Schwerdtfeger R, Baurmann $\mathrm{H}$ et al. Allogeneic stem cell transplantation after reduced-intensity conditioning in patients with myelofibrosis: a prospective, multicenter study of the Chronic Leukemia Working Party of the European Group for Blood and Marrow Transplantation. Blood 2009; 114: 5264-5270.

17 Zhang B, Lewis SM. The splenomegalyof myeloproliferative and lymphoproliferative disorders: splenic cellularity and vascularity. Eur I Haematol 1989; 43: 63-66.

18 Tefferi A. How I treat myelofibrosis. Blood 2011; 117: 3494-3504.

19 Cervantes F. Modern management of myelofibrosis. Br J Haematol 2005; 128: 583-592.

20 Lofvenberg E, Wahlin A, Roos G, Ost A. Reversal of myelofibrosis by hydroxyurea. Eur J Haematol 1990; 44: 33-38.

21 Manoharan A. Management of myelofibrosis with intermittent hydroxyurea. Br J Haematol 1991; 77: 252-254.

22 Martínez-Trillos A, Gaya A, Maffioli M, Arellano-Rodrigo E, Calvo $\mathrm{X}$, Díaz-Beyá $\mathrm{M}$ et al. Efficacy and tolerability of hydroxyurea in the treatment of the hyperproliferative manifestations of myelofibrosis: results in 40 patients. Ann Hematol 2010; 89: 1233-1237.

23 Tefferi A, Barosi G, Mesa RA, Cervantes F, Deeg J, Reilly JT et al. International Working Group consensus criteria for treatment response in myelofibrosis with myeloid metaplasia: on behalf of the IWG for myelofibrosis research and treatment (IWG-MRT). Blood 2006; 108: 1497-1503.

24 Oishi N, Swisher SN, Troup SB. Busulfan therapy in myeloid metaplasia. Blood 1960; 15: 863-872.

25 Petti MC, Latagliata R, Spadea T, Spadea A, Montefusco E, Aloe Spiriti MA et al. Melphalan treatment in patients with myelofibrosis with myeloid metaplasia. Br J Haematol 2002; 116: 576-581.

26 Tefferi A, Silverstein MN, Li C-Y. 2-Chlorodeoxyadenosine treatment after splenectomy in patients who have myelofibrosis with myeloid metaplasia. Br J Haematol 1997; 99: 352-357.

27 Barosi G, Liberato LN, Costa A, Ascari E. Cytoreductive effect of recombinant alpha interferon in patients with myelofibrosis with myeloid metaplasia. Blut 1988; 58: 271-274.

28 Gilbert HS. Long term treatment of myeloproliferative disease with interferon alpha-2b: feasibility and efficacy. Cancer 1998; 83 $1205-1213$.
29 Bachleitner-Hofmann T, Gisslinger H. The role of interferon-á in the treatment of idiopathic myelofibrosis. Ann Hematol 1999; 78: 533-538.

30 lanotto JC, Kiladjian JJ, Demory JL, Roy L, Boyer F, Rey J et al. PEG-IFN-alpha-2a therapy in patients with myelofibrosis: a study of the French Groupe d'Etudes des Myelofibroses (GEM) and France Intergroupe des syndromes Myeloproliferatifs (FIM). Br J Haematol 2009; 146: 223-225.

31 Mesa RA, Steensma DP, Pardanani A, Li CY, Elliott M, Kaufmann $\mathrm{SH}$ et al. A phase 2 trial of combination low-dose thalidomide and prednisone for the treatment of myelofibrosis with myeloid metaplasia. Blood 2003; 101: 2534-2541.

32 Marchetti M, Barosi G, Balestri F, Viarengo G, Gentili S, Barulli S et al. Low-dose thalidomide ameliorates cytopenias and splenomegaly in myelofibrosis with myeloid metaplasia: a phase II trial. J Clin Oncol 2004; 22: 424-431.

33 Merup M, Kutti J, Birgergard G, Mauritzson N, Björkholm M, Markevärn B et al. Negligible effects of thalidomide in patients with myelofibrosis with myeloid metaplasia. Med Oncol 2002; 19: 79-86.

34 Abgrall JF, Guibaud I, Bastie JN, Flesch M, Rossi JF, Lacotte-Thierry $\mathrm{L}$ et al. Thalidomide versus placebo in myeloid metaplasia with myelofibrosis: a prospective, randomized, double-blind, multicenter study. Haematologica 2006; 91: 1027-1032.

35 Tefferi A, Cortes J, Verstovsek S, Mesa RA, Thomas D, Lasho TL et al. Lenalidomide therapy in myelofibrosis with myeloid metaplasia. Blood 2006; 108: 1158-1164.

36 Benbassat J, Penchas S, Ligumski M. Splenectomy in patients with agnogenic myeloid metaplasia: an analysis of 321 published cases. Br J Haematol 1979; 42: 207-214.

37 Barosi G, Ambrosetti A, Buratti A, Finelli C, Liberato NL, Quaglini $\mathrm{S}$ et al. Splenectomy for patients with myelofibrosis with myeloid metaplasia: pretreatment variables and outcome prediction. Leukemia 1993; 7: 200-206.

38 Tefferi A, Mesa RA, Nagomey DN, Schroeder G, Silverstein MN. Splenectomy in myelofibrosis with myeloid metaplasia: a single-institution experience with 223 patients. Blood 2000; 95: 2226-2233.

39 López-Guillermo A, Cervantes F, Bruguera M, Pereira A, Feliu E, Rozman C. Liver dysfunction following splenectomy in idiopathic myelofibrosis: a study of 10 patients. Acta Haematol 1991; 85: 184-188.

40 Chaffanjon PC, Brichon PY, Ranchoup Y. Portal vein thrombosis following splenectomy for hematologic disease: retrospective study with Doppler color flow imaging. World J Surg 1998; 22: 1082-1086.

41 Barosi G, Ambrosetti A, Centra A, Falcone A, Finelli C, Foa P et al. Splenectomy and risk of blast transformation in myelofibrosis with myeloid metaplasia. Blood 1998; 91: 3630-3636.

42 Barbui T, Barosi G, Birgegard G, Cervantes F, Finazzi G, Griesshammer $\mathrm{M}$ et al. Philadelphia-negative classical myeloproliferative neoplasms: critical concepts and management recommendations from European LeukemiaNet. J Clin Oncol 2011; 29: 761-770.

43 Elliott MA, Chen MG, Silverstein MN, Tefferi A. Splenic irradiation for symptomatic splenomegaly associated with myelofibrosis with myeloid metaplasia. Br J Haematol 1998; 103: 505-511.

44 Wagner Jr H, McKeough PG, Desforges J, Madoc-Jones H. Splenic irradiation in the treatment of patients with chronic myelogenous leukemia or myelofibrosis with myeloid metaplasia. Results of daily and intermittent fractionation with and without concomitant hydroxyurea. Cancer 1986; 58: 1204-1207.

45 Bouabdallah R, Coso D, Gonzague-Casabianca L, Alzieu C, Resbeut M, Gastaut JA. Safety and efficacy of splenic irradiation in the treatment of patients with idiopathic myelofibrosis: a report on 15 patients. Leuk Res 2000; 24: 491-495.

46 Koeffler HP, Cline MJ, Golde DW. Splenic irradiation in myelofibrosis: effect on circulating myeloid progenitor cells. Br J Haematol 1979; 43: 69-77.

47 Pardanani A, Brown $\mathrm{P}$, neben-Wittich $\mathrm{M}$, Tobin $\mathrm{R}$, tefferi $\mathrm{A}$. Effective management of accelerated phase myelofibrosis with low-dose splenic radiotherapy. Am J Hematol 2010; 85: 715-716.

48 Verstovsek S, Kantarjian H, Mesa RA, Pardanani AD, CortesFranco J, Thomas DA et al. Safety and efficacy of INCB018424, a 
JAK1 and JAK2 inhibitor, in myelofibrosis. N Engl J Med 2010; 363: 1117-1127.

49 Verstovsek S, Mesa RA, Gottlib JR, Levy RS, Gupta V, Di Persio JF et al. Results of COMFORT-I, a randomized double-blind phase III trial of JAK $\frac{1}{2}$ inhibitor INCB18424 (424) versus placebo (PB) for patients with myelofibrosis (MF). J Clin Oncol 2011; 29(Suppl) abstract 6500.

50 Harrison CN, Kiladjian J, Al-Ali HK, Gisslinger R, Waltzman RJ, Stalbovskaya $\vee$ et al. Results of a randomized study of the JAK inhibitor ruxolitinib (INC424) versus best available therapy (BAT) in primary myelofibrosis (PMF), post-polycythemia vera-myelofibrosis (PPV-MF) or post-essential thrombocythemia-myelofibrosis (PET-MF). J Clin Oncol 2011; 29(Suppl) abstract LBA6501.

51 Pardanani A, Gotlib JR, Jamieson C, Cortes JE, Talpaz M, Stone RM et al. Safety and efficacy of TG101348, a selective JAK2 inhibitor, in myelofibrosis. J Clin Oncol 2011; 29: 789-796.
52 Santos FP, Kantarjian HM, Jain N, Manshouri T, Thomas DA, Garcia-Manero G et al. Phase II study of CEP-701, an orally available JAK2 inhibitor, in patients with primary or post polycythemia vera/essential thrombocythemia myelofibrosis. Blood 2010; 115: 1131-1136.

53 Pardanani AD, Caramazza D, George G, Lasho T, Hogan WJ, Litzow MR et al. Safety and efficacy of CYT387, a JAK $\frac{1}{2}$ inhibitor, for the treatment of myelofibrosis. J Clin Oncol 2011; 29(Suppl) abstract 6614 .

This work is licensed under the Creative Commons Attribution-NonCommercial-No Derivative Works 3.0 Unported License. To view a copy of this license, visit http:// creativecommons.org/licenses/by-nc-nd/3.0/ 